\title{
Efeito do tratamento com óleos essenciais sobre a qualidade fisiológica e sanitária das sementes de milho (Zea mays)*
}

\author{
Effect of essential oils on the physiological and \\ sanitary quality of maize seed (Zea mays)
}

\author{
Maria Paula Domene ${ }^{\text {**}}$, Eduardo Micotti da Glória², João Domingos Biagi³, \\ Benedito Carlos Benedetti ${ }^{3}$, Leila Martins ${ }^{1}$
}

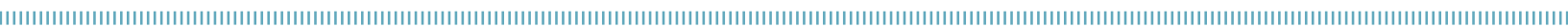

RESUMO: O desenvolvimento de pesticidas é uma constante no setor agropecuário, visando oferecer produtos menos agressivos ao meio ambiente e novos princípios ativos, evitando o aparecimento de resistência. $\mathrm{O}$ estudo de alternativas aos fungicidas utilizados no tratamento de sementes tem nos óleos essenciais um campo para prospecção. Esta pesquisa teve como objetivo avaliar os efeitos dos óleos essenciais provenientes de folhas de C. citriodora e E. camaldulensis, em sementes de milho da variedade AL Bandeirante, de diferentes localidades. A qualidade fisiológica e sanitária das sementes foi avaliada quando se trataram as amostras utilizando os óleos individualmente, a mistura equitativa desses óleos e o tratamento com um antifúngico comercial. Foi observado que o tratamento com os óleos C. citriodora e E. camaldulensis e a mistura dos óleos não afetou a germinação imediata das sementes de Avaré. No lote de Bernardino de Campos, o tratamento com C. citriodora foi prejudicial; com o E. camualdulensis, apesar de não diferenciar estatisticamente dos demais, diminuiu a germinação, o que impediria sua utilização como semente, segundo o padrão normatizado (de $85 \%$ ) pelo Ministério da Agricultura, Pecuária e Abastecimento (MAPA). O óleo de E. camaldulensis apresentou efeito fitotóxico, diminuindo o comprimento das plântulas; a acetona utilizada como solvente não influenciou sobre a germinação, mas apresentou efeito fitotóxico após o envelhecimento acelerado. A aplicação dos óleos isoladamente foi capaz de diminuir a incidência dos fungos dos gêneros Penicillium e Fusarium, mas para Aspergillus o comportamento foi semelhante ao antifúngico comercial, não apresentando efeito quando comparado ao tratamento testemunha.

PALAVRAS-CHAVE: Corymbia citriodora; Eucalyptus camaldulensis; qualidade fisiológica; patologia de sementes.

\begin{abstract}
The development of pesticides is a constant in the agricultural sector in order to offer products less aggressive to the environment and new active ingredients, preventing the emergence of resistance. The alternative study to fungicides used for seed treatment has the essential oils field for prospecting. This research aimed to evaluate the effects of essential oils from leaves of C. citriodora and E. camaldulensis in maize seed variety AL Bandeirante, from different locations. The physiological and sanitary quality of the seeds were evaluated when treated samples using the oils individually, equal mixture of these oils and treatment with a commercial antifungal. It was observed that the treatment with the oils C. citriodora, E. camaldulensis and the mixture of oils did not affect the immediate germination of seeds Avare. In the batch Bernardino de Campos, treatment with $C$. citriodora was harmful and E. camualdulensis, although not statistically differ from the others, decreased germination which would prevent its use as seed, according to the standard regulated by the Ministry of Agriculture, Livestock and Supply (MAPA), 85\%. The E. camaldulensis oil showed phytotoxic effect decreasing the length of seedlings, acetone used as a solvent had no effect on germination but showed phytotoxic effect after accelerated aging. The application of oils alone was able to reduce the incidence of fungi of the genus Penicillium and Fusarium, Aspergillus but the behavior was similar to commercial antifungal, showing no effect when compared to the control treatment.
\end{abstract}

KEYWORDS: Corymbia citriodora; Eucalyptus camaldulensis; physiological quality; seed pathology.

'Centro de Produção de Sementes, Departamento de Sementes, Mudas e Matrizes, Coordenadoria de Assistência Técnica Integral (CATI) - Campinas (SP), Brasil. ${ }^{2}$ Departamento de Agroindústria, Alimentos e Nutrição, Escola Superior de Agricultura Luiz de Queiroz, Universidade de São Paulo (ESALQ/USP) - Piracicaba (SP), Brasil. ${ }^{3}$ Faculdade de Engenharia Agrícola, Universidade Estadual de Campinas (FEAGRI/UNICAMP) - Campinas (SP), Brasil.

*Parte integrante da Tese de Doutorado pela FEAGRI/UNICAMP da primeira autora.

**Autor correspondente: paula.domene@cati.sp.gov.br

Recebido em: 03/02/2014. Aceito em: 28/03/2015 


\section{INTRODUÇÃO}

O milho constitui-se na segunda maior safra de grãos produzida no Brasil. No ano de 2012, foram produzidas 72,78 milhóes de toneladas desse cereal, o que representou aproximadamente $43,9 \%$ da safra de grãos (Portal Brasil, 2013).

Segundo Shipanski (2011), a produção nacional tem crescido a uma taxa superior a $5 \%$ ao ano e o principal componente desse crescimento foi a elevação da produtividade média, que passou de $1.840 \mathrm{~kg} / \mathrm{ha}$, na safra 1990/91, para $4.316 \mathrm{~kg} / \mathrm{ha}$, na safra 2009/10.

A produtividade da cultura do milho pode ser influenciada por fatores como disponibilidade hídrica, fertilidade do solo, populaçáo de plantas, sistema de cultivo, potencial produtivo do híbrido e manejo de plantas daninhas, pragas e doenças (SANDini; Fancelli, 2000).

As sementes de milho infectadas por fungos constituem-se em importantes fontes de inóculos, cujos patógenos podem causar podridóes de sementes, morte de plântulas em pré e pós-emergência e podridóes radiculares, o que leva à formação de lavouras com baixa populaçáo de plantas (Pinto, 1993).

Segundo Fancelli; Dourado (2000), o tratamento de sementes contribui para a manutenção do estande, além de reduzir a disseminação de vários patógenos. Falhas na emergência refletem-se diretamente na densidade final de plantas e, consequentemente, na produtividade, pelo fato de o milho ter uma baixa capacidade de compensação efetiva entre plantas.

O tratamento de sementes normalmente é realizado por meio de fungicidas sintéticos com diferentes princípios ativos; contudo, novos princípios ativos são constantemente estudados, entre eles os provenientes de fonte natural, como os extratos vegetais e os óleos essenciais (Hillen et al., 2012; Christian; GogGI, 2008). Os óleos essenciais, obtidos por intermédio de diferentes processos a partir de matéria-prima vegetal, são composições de substâncias com diferentes funções químicas, tais como aldeídos, alcoóis, fenóis, cetonas, etc. (SELL, 2010).

O potencial antifúngico de alguns óleos essenciais diante de diferentes fungos patogênicos existentes no ambiente agrícola tem sido bastante avaliado, mostrando que muitos apresentam excelente atividade antifúngica (PAuli; ScHILCHER, 2010). Dessa maneira, é pertinente concluir que os óleos essenciais possam ser utilizados em tratamentos sanitários de sementes, contudo o efeito desses óleos sobre a germinação e o desenvolvimento das plântulas precisa ser também investigado (Christian; Goggi, 2008). Os estudos para verificar a viabilidade do emprego dos óleos podem indicar estes como possíveis substitutos aos antifúngicos já utilizados e também revelar novas moléculas a serem utilizadas para síntese de novos antifúngicos comerciais (DuKe et al., 2010).

Dentre as possíveis fontes vegetais, espécies de Eucaliptus e, mais recentemente, de Corymbia, gêneros pertencentes à família Myrtaceae, têm sido bastante estudadas como fontes de óleos com bioatividade para serem utilizados como pesticidas naturais (BATish et al., 2008). Para as espécies C. citriodora e E. camaldulensis, não foram encontrados relatos de avaliaçóes da utilização dos óleos das folhas dessas espécies no controle de fungos de sementes de milho, bem como do efeito da aplicação desses óleos sobre a qualidade fisiológica das sementes. Assim, esta pesquisa teve como objetivo verificar o efeito da utilização dos óleos provenientes das folhas dessas duas espécies sobre a germinaçấo e o vigor de sementes de milho.

\section{MATERIAL E MÉTODOS}

Os testes para determinar a qualidade fisiológica e sanitária das sementes foram conduzidos no Laboratório de Sementes do Departamento de Sementes, Mudas e Matrizes da Coordenadoria de Assistência Técnica Integral (DSMM/CATI) e no Laboratório de Tecnologia Pós-colheita da Faculdade de Engenharia Agrícola da Universidade Estadual de Campinas (FEAGRI/ UNICAMP), em Campinas (SP).

As sementes utilizadas foram da variedade AL Bandeirante e provenientes de campos de produção de sementes do DSMM/ CATI, situados nos municípios de Avaré e Bernardino de Campos.

Para o tratamento das sementes, foram utilizados os óleos essenciais provenientes de folhas de C. citriodora e E. camaldulensis. As folhas foram obtidas no Horto Florestal de Itatinga (SP), pertencente à Escola Superior de Agricultura Luiz de Queiroz da Universidade de São Paulo (ESALQ/USP). A extração dos óleos foi realizada no Laboratório de Micotoxinas e Micologia, do Departamento de Agroindústria, Alimentos e Nutrição da ESALQ/USP, por meio de hidrodestilação por quatro horas, utilizando-se um aparelho tipo Clevenger. Os óleos obtidos foram passados por uma camada de sulfato de sódio anidro, visando extrair qualquer residual de água, e armazenados em frasco âmbar até sua utilização.

Seis tratamentos foram realizados, sendo eles:

1. sementes tratadas com óleo de C. citriodora;

2. sementes tratadas com óleo de E. camaldulensis;

3. sementes tratadas com o fungicida comercial Captan 500 (controle positivo);

4. sementes tratadas com o solvente dos óleos, a acetona;

5. sementes tratadas com a mistura binária dos óleos; e

6. sementes sem tratamento (testemunha).

Para aplicação dos tratamentos com óleos isoladamente, $850 \mathrm{~g}$ de sementes foram imersos durante 10 minutos em uma solução de $500 \mathrm{~mL}$ de acetona $+1,7 \mathrm{~mL}$ de cada óleo. A acetona foi utilizada para promover uma boa dispersão dos óleos. Testes preliminares no laboratório demonstraram que a acetona promoveu melhor efeito emulsionável do que o Tween. No caso do tratamento com a mistura de óleos, $0,85 \mathrm{~mL}$ de cada óleo foi adicionado a $500 \mathrm{~mL}$ de acetona. No tratamento com acetona, as sementes foram imersas em $500 \mathrm{~mL}$ de acetona pura. 
O tratamento com o fungicida Captan 500 (controle positivo) foi realizado colocando-se $300 \mathrm{~mL}$ de uma solução aquosa do fungicida em um saco plástico e acrescentado $850 \mathrm{~g}$ de sementes a serem tratadas. $\mathrm{O}$ saco foi fechado e procedeu-se à agitação do recipiente, para promover o contato da soluçáo com as sementes e uma distribuição homogênea na massa de sementes. A dose do fungicida na semente seguiu o recomendado pelo fabricante, ou seja, $240 \mathrm{~g}$ do produto $/ 100 \mathrm{~kg}$ de sementes.

As variáveis mensuradas para avaliação do efeito dos tratamentos sobre a qualidade fisiológica, do vigor e sanitária das sementes foram:

- $\quad$ percentagem de germinação;

- envelhecimento acelerado;

- comprimento de plântulas; e

- $\quad$ sanidade.

Para caracterizaçáo física das sementes, foi mensurada a umidade.

A umidade das sementes foi determinada pelo método de estufa a $105 \pm 3^{\circ} \mathrm{C}$ durante 24 horas, utilizando duas repetiçôes, de $10 \mathrm{~g}$ cada, de acordo com as Regras de Análise de Sementes (RAS) (Brasil, 2009).

As sementes foram submetidas ao teste de germinação em rolo de papel, segundo as RAS. Assim, foram analisadas 800 sementes por tratamento, distribuídas em 32 repetiçóes de 25 sementes. As sementes foram mantidas em câmaras de germinação, reguladas a temperatura constante de $25 \pm 3^{\circ} \mathrm{C}$, sendo 8 horas mantidas sob luz e 16 horas no escuro. A avaliação foi feita no sétimo dia, após a semeadura.

Dez plântulas normais, provenientes do teste de germinação, foram medidas registrando-se o comprimento total (os resultados foram obtidos pela média do tamanho das plântulas). Para a seleção das plântulas normais, o papel de germinação foi dividido em três partes, sendo coletadas três plântulas normais do primeiro terço e à direita do papel, três do segundo terço e à esquerda do papel e quatro do terceiro terço e no centro do papel. Foram analisadas 320 plântulas por tratamento, perfazendo 32 repetiçôes de 10 plântulas, segundo metodologia adaptada de Vieira; Carvalho (1994).

Para o teste de envelhecimento acelerado, as sementes foram acondicionadas sobre uma bandeja de telas acopladas às caixas gerbox, contendo, ao fundo, $40 \mathrm{~mL}$ de água destilada. Os gerbox foram colocados em câmara apropriada para o envelhecimento acelerado, por 96 horas, a $42^{\circ} \mathrm{C}$ (KrzYZANowski et al., 1999). Para cada tratamento, 4 repetiçóes foram montadas contendo 200 sementes. Após esse período, as sementes foram submetidas ao teste de germinação, como descrito.

Para determinação da microflora presente nas sementes, foi utilizado o teste de incubação em papel de filtro (Blotter test). O teste foi constituído de 10 sementes por placa, com 20 repetiçóes, totalizando 200 sementes por tratamento, segundo metodologia descrita por MaCHADo (2000).
Os resultados obtidos foram submetidos à análise de variância pelo teste $\mathrm{F}$, e as médias foram comparadas pelo teste de Tukey, a 5\% de probabilidade. Todas as análises foram realizadas com o auxílio do programa estatístico ASSISTAT, versão 7.5 beta (Silva; Azevedo, 2002).

\section{RESULTADOS E DISCUSSÃO}

A caracterização da qualidade física das sementes dos campos de Avaré e Bernardino de Campos mostrou que as sementes apresentavam-se, imediatamente antes de sua utilização nos ensaios, com umidade de 10,4 e 11,4\% e germinação de 88 e $86 \%$, respectivamente. Portanto, apresentavam-se com reduzida umidade e com germinação acima do mínimo de $85 \%$ estabelecido pela Instrução Normativa no 45 (MAPA, 2013) (Tabela 1).

Com base nos resultados de germinação, é possível observar um comportamento semelhante entre os lotes de sementes avaliados (Tabela 2). Nas amostras de sementes de Avaré, não houve diferença estatística entre os tratamentos. Isso sugere que não ocorreu efeito fitotóxico sobre a germinação. No lote de sementes de Bernardino de Campos, o tratamento com fungicida foi equivalente ao tratamento com óleo de E. camaldulensis e a mistura de óleos, mas o tratamento com óleo de C. citriodora reduziu a germinação das sementes. Entretanto, apesar de o tratamento com E. camaldulensis nâo ter diferenciado da testemunha, a germinação estava abaixo de $85 \%$, o que reprovaria o lote para venda como semente. $\mathrm{O}$ efeito dos óleos essenciais sobre a germinação das sementes parece ser dependente do óleo essencial utilizado e da dose empregada. Hillen et al. (2012) observaram que os óleos de palmarosa (Cymbopogon martinii) e candeia (Eremanthuse rythropappus) melhoraram a germinação das sementes de milho expostas à fumigação com os voláteis desses óleos, enquanto os voláteis do óleo de alecrim (Rosmarinus officinalis) diminuíram. Rossi et al. (2012), estudando alguns óleos essenciais extraídos de plantas da região do Mediterrâneo, Laurus nobilis, Citrus bergamia, Foeniculum vulgare e Lavandula bybrida, demonstraram um efeito inibitório da germinação de sementes de trigo e milho; contudo, a diminuição foi mais pronunciada quando a dose do óleo na solução de tratamento foi elevada de 1 para $50 \%$. Esse mesmo trabalho relata o efeito detrimental, para germinação, provocado pelo solvente, no caso metanol, utilizado como diluente na aplicação dos óleos. Christian; Goggi (2008) relataram que o uso de 18 tipos de

Tabela 1. Qualidade inicial de amostras de lotes de sementes de milho.

\begin{tabular}{lccc} 
& $\begin{array}{c}\text { Pureza } \\
(\%)\end{array}$ & $\begin{array}{c}\text { Umidade } \\
(\%)\end{array}$ & $\begin{array}{c}\text { Germinação } \\
(\%)\end{array}$ \\
\hline Avaré & 100 & 10,4 & 88 \\
\hline B. Campos & 100 & 11,4 & 86 \\
\hline
\end{tabular}


óleos essenciais não mostrou efeito fitotóxico, mesmo utilizando uma dose 20 vezes superior a mínima dose inibitória observada para cada um dos fitopatógenos.

A germinação inferior de sementes de milho tratadas com alguns óleos essenciais, em comparação com sementes tratadas com um fungicida sintético, como no lote de sementes de Avaré, já havia sido observada por CHRISTIAN; GogGi (2008), quando utilizaram o fungicida comercial Maxim XL. O comportamento diferente verificado para os gráos de Bernardino de Campos, no qual as sementes tratadas com óleo não diferiram da semente tratada com o fungicida comercial Captan, pode ser derivado de alguma característica resultante do processo de produçáo de sementes desse local que tenha influenciado na germinaçáo a ponto de o tratamento com fungicida não conseguir expressar um diferencial.

A avaliação dos resultados dos testes de vigor mostrou que o lote de Bernardino de Campos apresentava-se com qualidade fisiológica inferior ao lote de Avaré (Tabela 2). A aplicação com fungicida não afetou a germinaçáo das sementes expostas ao estresse do envelhecimento acelerado em comparação à testemunha, contudo a aplicação da acetona e dos óleos isoladamente ou em combinaçáo afetou a fisiologia das sementes, reduzindo a germinação após o envelhecimento acelerado. Isso demonstrou que a acetona e os óleos apresentaram efeito fitotóxico sobre as sementes submetidas ao protocolo de envelhecimento acelerado utilizado, sendo mais prejudicial o óleo de $C$. citriodora para sementes menos vigorosas, como o lote de Bernardino de Campos.

Os resultados do comprimento de plântulas também mostraram um comportamento semelhante para os dois lotes de sementes avaliados, ou seja, a maioria dos tratamentos não prejudicou o desenvolvimento da plântula, pois náo diferiu da testemunha. A exceção foi o óleo essencial de E. camaldulensis, que diminuiu o comprimento de plântula. Alves et al. (2004) estudaram a ação sobre sementes de alface dos óleos essenciais de canela (Cinnamomum zeylanicum), alecrim-pimenta (Lippia sidoides), capim-citronela (Cymbopogon citratus), alfavaca-cravo (Ocimum gratissimum) e jaborandi (Policarpus microphyllus) e observaram um efeito alelopático dependente da concentração, ora reduzindo, ora inibindo o crescimento da plântula de alface, para a maioria dos óleos estudados, com exceção para o óleo de jaborandi, que estimulou o crescimento das plântulas. Ribeiro; Lima (2012) mostraram também um efeito inibitório do óleo essencial da casca da laranja (Citrus sinensis) no desenvolvimento das plântulas de duas espécies de ervas daninhas: Euphorbia heterophylla L. e Ipomoea grandifolia.

A análise dos resultados do teste de sanidade, apresentados na Tabela 3, permite observar que, de modo geral, o melhor tratamento para redução da incidência dos fungos dos gêneros Penicillium e Fusarium consistiu-se na aplicaçáo do antifúngico comercial. Exceção feita para Penicillium, no lote de Bernardino de Campos, em que o óleo C. citriodora apresentou melhor controle em relaçáo a todos os tratamentos.

Em relação aos óleos, o melhor controle, nas amostras dos dois lotes, no que diz respeito ao gênero Penicillium, foi obtido com o óleo de $C$. citriodora, que também se mostrou eficiente para Fusarium no lote de Avaré. Já para as amostras provenientes de Bernardino de Campos o óleo de E. camaldulensis foi mais efetivo para o controle de Fusarium.

A aplicaçáo da mistura de óleos náo promoveu um efeito sinérgico ou aditivo, apresentando efeitos semelhantes à acetona e aos tratamentos isolados de óleos, em ambas as amostras, não compensando o gasto a mais de óleo para o efeito encontrado. Fu et al. (2007), estudando o efeito antimicrobiano dos óleos essenciais de Syzygium aromaticum e Rosmarinus officinalis, demonstraram que a combinação desses óleos apresentou um efeito aditivo e sinérgico para diferentes espécies de bactérias e levedura; entretanto, para o fungo Aspergillus niger, esses efeitos não foram visualizados.

O tratamento com acetona sugere que o solvente apresentou pouca ação antifúngica, sendo observada para Penicillium e Fusarium, nas amostras de Bernardino de Campos e Avaré,

Tabela 2. Testes de germinação, envelhecimento acelerado e comprimento de plântulas de amostras de sementes provenientes de Avaré e Bernardino de Campos, submetidas a diferentes tratamentos.

\begin{tabular}{lcccccc} 
& \multicolumn{7}{c}{ Testes } \\
\cline { 2 - 7 } Tratamentos & \multicolumn{2}{c}{ G (\%) } & \multicolumn{2}{c}{ EA (\%) } & \multicolumn{1}{c}{ CPL (cm) } \\
\cline { 2 - 7 } & Avaré & B. Campos & Avaré & B. Campos & Avaré & B. Campos \\
\hline Testemunha & $88 \mathrm{abc}$ & $86 \mathrm{a}$ & $88 \mathrm{a}$ & $84 \mathrm{a}$ & $116,9 \mathrm{a}$ & $114,6 \mathrm{ab}$ \\
\hline Acetona & $90 \mathrm{ab}$ & $87 \mathrm{a}$ & $52 \mathrm{~d}$ & $33 \mathrm{~d}$ & $126 \mathrm{a}$ & $112,7 \mathrm{ab}$ \\
\hline Fungicida & $92 \mathrm{a}$ & $87 \mathrm{a}$ & $88 \mathrm{a}$ & $88 \mathrm{a}$ & $129,6 \mathrm{a}$ & $118,6 \mathrm{ab}$ \\
\hline C. citriodora & $85 \mathrm{c}$ & $72 \mathrm{~b}$ & $67 \mathrm{c}$ & $45 \mathrm{c}$ & $120,4 \mathrm{a}$ & $99,4 \mathrm{bc}$ \\
\hline E. camaldulensis & $87 \mathrm{bc}$ & $83 \mathrm{a}$ & $70 \mathrm{bc}$ & $55 \mathrm{~b}$ & $78,2 \mathrm{~b}$ & $82,6 \mathrm{c}$ \\
\hline C. citriodora + E. camaldulensis & $87 \mathrm{bc}$ & $85 \mathrm{a}$ & $75 \mathrm{~b}$ & $58 \mathrm{~b}$ & $125,3 \mathrm{a}$ & $143,2 \mathrm{a}$ \\
\hline CV (\%) & 7,0 & 8,6 & 12,4 & 14,2 & 27,2 & 27,2 \\
\hline
\end{tabular}

Médias seguidas da mesma letra minúscula na coluna não diferem entre si pelo teste de Tukey a $5 \%$ de probabilidade. G: germinação; EA: envelhecimento acelerado; CPL: comprimento de plântulas; CV: coeficiente de variação. 
Tabela 3. Porcentagem média de incidência de fungos patogênicos em amostras de sementes de milho submetidas a diferentes tratamentos.

\begin{tabular}{|c|c|c|c|c|c|c|}
\hline \multirow{3}{*}{ Tratamentos } & \multicolumn{6}{|c|}{ Fungos (\%) } \\
\hline & \multicolumn{2}{|c|}{ Aspergillus spp. } & \multicolumn{2}{|c|}{ Penicillium spp. } & \multicolumn{2}{|c|}{ Fusarium sp. } \\
\hline & Avaré & B. Campos & Avaré & B. Campos & Avaré & B. Campos \\
\hline Testemunha & $1,6 \mathrm{c}$ & $3,4 \mathrm{~d}$ & 19,8 a & $23,4 \mathrm{a}$ & $19,8 \mathrm{a}$ & $19,8 \mathrm{a}$ \\
\hline Acetona & $8,5 \mathrm{a}$ & $4,7 \mathrm{~cd}$ & $20.8 \mathrm{a}$ & $19 b$ & $14,4 b$ & 19,8 a \\
\hline Fungicida & $0,5 c$ & $8,8 b$ & $5,0 \mathrm{~d}$ & $8,8 \mathrm{c}$ & $0,00 \mathrm{e}$ & $3,8 d$ \\
\hline C. citriodora & $4,5 b$ & $5,3 c$ & $8,6 c$ & $5,3 d$ & $2,9 d$ & $11,6 b$ \\
\hline E. camaldulensis & $0,7 \mathrm{c}$ & $20 \mathrm{a}$ & $13,2 b$ & $20 \mathrm{~b}$ & $9,8 \mathrm{c}$ & $7,7 \mathrm{c}$ \\
\hline C. citriodora + E. camaldulensis & $10 \mathrm{a}$ & $20 \mathrm{a}$ & 20,8 a & $20 \mathrm{~b}$ & $14,3 b$ & $13,1 \mathrm{~b}$ \\
\hline CV (\%) & 62,8 & 23,4 & 23,5 & 26,3 & 26,5 & 21,7 \\
\hline
\end{tabular}

Médias seguidas da mesma letra minúscula na coluna não diferem entre si pelo teste de Tukey a $5 \%$ de probabilidade.

CV: coeficiente de variação.

respectivamente. O efeito antifúngico dos solventes utilizados para dissolver os óleos essenciais em avaliaçôes da capacidade antifúngica já foi relatado na literatura (Sharma; SAHARMA, 2011).

Para o gênero Aspergillus, os tratamentos não foram efetivos para o lote de Bernardino de Campos; contudo, o óleo de E. camaldulensis apresentou o mesmo desempenho para o lote de Avaré, quando comparado ao fungicida comercial.

\section{CONCLUSÕES}

Entre as observaçóes, pode-se inferir que não houve efeito fitotóxico para a germinação imediata das sementes, com exceção para o tratamento com o óleo de C. citriodora, em amostras de Bernardino de Campos.

Os testes de vigor apresentaram divergências quanto a diferenciar a possível toxicidade dos óleos ao longo do tempo. O teste de envelhecimento acelerado acusou o óleo de C. citriodora afetando o vigor das sementes, e o óleo de E. camaldulensis causou uma diminuição no comprimento de plântulas.

A incidência de fungos também foi afetada de forma diferenciada pelos tratamentos nos dois lotes de sementes. Como característica geral, os óleos essenciais, quando utilizados isoladamente, conseguiram reduzir a incidência de fungos dos gêneros Penicillium e Fusarium. Para o gênero Aspergillus, os tratamentos não controlaram o desenvolvimento do patógeno nas amostras de Bernardino de Campos, mas o tratamento com o óleo de E. camaldulensis foi efetivo no controle desse patógeno, equiparando-se ao fungicida comercial.

Os resultados apresentados demonstram que os tratamentos com os óleos essenciais, separadamente, são viáveis para o tratamento de sementes, controlando os fungos Penicillium e Fusarium, sendo relevante a continuidade da pesquisa para avaliar a dosagem, o diluente e a eficiência do tratamento durante o armazenamento das sementes.

\section{AGRADECIMENTOS}

Ao Conselho Nacional de Desenvolvimento Científico e Tecnológico $(\mathrm{CNPq})$, pelo apoio financeiro à pesquisa.

À Escola Superior de Agricultura Luiz de Queiros da Universidade de Sáo Paulo (ESALQ/USP), por meio do Laboratório de Micotoxinas e Micologia, do Departamento de Agroindústria, Alimentos e Nutrição, pela extração dos óleos essenciais e avaliaçấo dos resultados.

À Coordenadoria de Assistência Técnica Integral (CATI), por meio do Departamento de Sementes, Mudas e Matrizes (DSMM), pelas sementes cedidas.

À Universidade Estadual de Campinas (UNICAMP), por intermédio do Laboratório de Pós-Colheita, da Faculdade de Engenharia Agrícola, por proporcionar a realizaçáo do Curso de Doutorado e pelas análises realizadas.

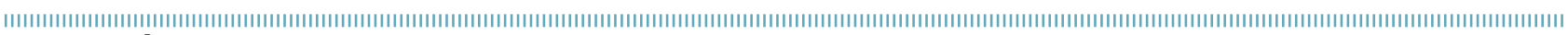
REFERÊNCIAS

ALVES, M.C.S.; MEDEIROS FILHO, S.M.; INNECCO, R.; TORRES, S.B. Alelopatia de extratos voláteis na germinação de sementes e no comprimento da raiz de alface. Pesquisa Agropecuária Brasileira, Brasília, v.39, n.11, p.1083-1086, 2004.
BATISH, D.R.; HARMINDER, P.S.; KOHLI, R.K.; KAUR, S. Eucalyptus essential oil as a natural pesticide. Forest Ecologyand Management, 256, p.2166-2174, 2008. 
BRASIL. Ministério da Agricultura, Pecuária e Abastecimento. Regras para análise de sementes. Brasília: MAPA/ACS, 2009. 395p.

CHRISTIAN, E.J.; GOGGI, A.S. Aromatic plant oils as fungicide for organic corn production. Crop Science, v.48, p. 1941-1951, 2008.

DUKE, S.O.; CANTRELL, C.L. MEEPAGALA, K.M.; WEDGE, D.E.; TABANCA, N.; SCHRADER, K.K. Natural toxins for use in pest management. Toxins, v.2, p.1943-1962, 2010.

FANCELLI, A.L.; DOURADO NETO, D. Produção de milho. Guaiba: Agropecuária, 2000. 360p.

FU, Y.; ZU, Y.; CHEN, L.; SHI, X.; WANG, Z. SUN, S.; EFFERTH, T. Antibimicrobial activity of clove and rosemary essential oils alone and in combination. Phytotherapy Research, v.21, p.989-994, 2007.

HILLEN, T.; SCHWAN-ESTRADA, K.R.F.; MESQUINI, R.M.; CRUZ, M.E.S.; STANGARLIN, J.R.; NOKAZI, M. Atividade antimicrobiana de óleos essenciais no controle de fitopatógenos fúngicos in vitro e no tratamento de sementes. Revista Brasileira de Plantas Medicinais, Botucatu, v.14, n.3, p.439-445, 2012.

KRZYZANOWSKI, F.C.; VIEIRA, R.D; FRANÇA-NETO, J.B. (Eds.). Vigor de sementes: conceitos e testes. Londrina: ABRATES, 1999. p.1.1-1.21.

MACHADO, J.C. Tratamento de sementes - controle de doenças. Lavras: LAPS/UFLA/FAEPE, 2000. 138p.

PAULI, A.; SCHILCHER, $\mathrm{H}$. In vitro antimicrobial activities of essential oils monographed in the European pharmacopoeia $6^{\text {th }}$ edition. In: Base, K.H.C.; BUCHBAUER, G. (Ed.). Handbook of essential oils, science, technology and applications. Boca Raton, FL: CRC Press, 2010. p.353-548.

PINTO, N.F.J. Tratamento das sementes com fungicidas. In: Tecnologia para produção de sementes de milho. Sete Lagoas: EMBRAPA, CNPMS, 1993. p.43-47 (Circular Técnica, 19).
PORTAL BRASIL. Safra de grãos no País bate recorde e atinge 165,9 milhões de toneladas. Disponível em: <http://www.brasil.gov.br/ noticias/arquivos/2012/08/09/safra-de-graos-no-pais-baterecorde-e-atinge-165-9-milhoes-de-toneladas >. Acesso em: 19 jun. 2013.

RIBEIRO, J.P.N.; LIMA, M.I.S. Allelopathic effects of orange (Citrussinensis L.) peel essential oil. Acta Botanica Brasilica, v.26, n. 1, p.256-259, 2012.

ROSSI, E.; COSIMI, S.; LONI, A. Bioactivity of essential oils from Mediterranean plants: Insecticidal properties on Sitophiluszeamais and effects on seed germination. Journal of Entomology, v.9, n.6, p.403-412, 2012.

SANDINI, I.E.; FANCELLI, A.L. Milho: estratégias de manejo para a região sul. Guarapuava: Fundação Agrária de Pesquisa Agropecuária, 2000. 209p.

SCHIPANSKI, C.A. Tratamento de sementes de milho com fungicidas $e$ indutor de resistência e pulverização foliar para o controle da ferrugem comum do milho (Pucciniasorghi Schw.). Dissertação (Mestrado em Agronomia) - Universidade Estadual de Ponta Grossa, Ponta Grossa, 2011.

SELL, C. Chemistry of essential oils. In: Base, K.H.C.; BUCHBAUER, G. (Ed.). Handbook of essential oils, science, technology and applications. Boca Raton, FL: CRC Press, 2010. p.121-150.

SHARMA, A.; SHARMA, K. Should solubility and zone of inhibition be the only criteria for selection of solvent in antimicrobial assay? Advances in Biological Research, v.5, n.5, p.241-247, 2011.

SILVA, F.A.S.; AZEVEDO, C.A.A.V. Versão do programa computacional Assistat para o sistema operacional Windows. Revista Brasileira de Produtos Agroindustriais, Campina Grande, v.4, n.1. p.71-78, 2002.

VIEIRA, R.D.; CARVALHO, N.M Testes de vigor em sementes. Jaboticabal: FUNEP/UNESP, 1994. 164p. 